\title{
HEIMANN, Heinz-Dieter, HLAVÁČEK, Ivan, Kommunikationspraxis und Korrespondenzwesen im Mittelalter und in der Renaissance
}

\section{Pierre Monnet}

\section{(2) OpenEdition \\ Journals}

Édition électronique

URL : http://journals.openedition.org/ifha/1362

DOI : 10.4000/ifha.1362

ISSN : 2198-8943

Éditeur

IFRA - Institut franco-allemand (sciences historiques et sociales)

Référence électronique

Pierre Monnet, «HEIMANN, Heinz-Dieter, HLAVÁČEK, Ivan, Kommunikationspraxis und Korrespondenzwesen im Mittelalter und in der Renaissance », Revue de I'IFHA [En ligne], Date de recension, mis en ligne le 01 janvier 1999, consulté le 22 septembre 2020. URL : http:// journals.openedition.org/ifha/1362 ; DOI : https://doi.org/10.4000/ifha.1362

Ce document a été généré automatiquement le 22 septembre 2020.

(CIFHA 


\title{
HEIMANN, Heinz-Dieter, HLAVÁČEK, Ivan,
} Kommunikationspraxis und Korrespondenzwesen im Mittelalter und in der Renaissance

\author{
Pierre Monnet
}

H.-D. HEIMANN, déjà connu pour ses travaux sur le système des messagers et des envoyés de la ville de Cologne, et I. HLAVACEK, spécialiste reconnu de l'histoire des pays de Bohême au Moyen Âge, ont rassemblé dans ce recueil treize contributions consacrées à l'échange des nouvelles, de la correspondance et des informations politiques dans la société médiévale. Ce thème bénéficie actuellement d'un très large intérêt chez les médiévistes, sans doute en liaison avec une »renaissance« de l'histoire diplomatique enfin sortie des traités. Les auteurs ont résolument choisi de ne négliger aucun des niveaux de la société concernés par l'échange organisé et massif des informations aux XIVe et XVe ss: la papauté avec Franz-J. FELTEN, la royauté avec I. HLAVACEK et Paul-Joachim HEINIG, les principautés territoriales, telle celle des Teutoniques avec Hartmut BOOCKMANN et Klaus NEITMANN, ou bien encore le monde des villes avec Miloslav POLIVKA sur Nuremberg ou la circulation des savoirs dans les écoles (Martin KINTZINGER), sans oublier les historiens contemporains qui firent grand usage de ce matériel documentaire de premier ordre (Marie BLAHOVA). Le grand intérêt du volume est également de porter la réflexion en direction de la matérialité de la correspondance et de ses effets sur le contenu et la transmission des nouvelles: lettres ouvertes (Erdmann WEYRAUCH) ou lettres scellées (Hermann MAUE) sont autant d'indicateurs des intentions avouées ou dissimulées de leurs auteurs et induisent certains comportements dans la remise aux destinataires qui autorisent une ritualisation de l'échange épistolaire. Cette histoire des formes et fonctions de la lettre (qui n'a pas chassé mais toujours accompagné le message oral) ouvre ainsi des perspectives nouvelles sur cette civilisation des media que fut aussi la société 
médiévale, et éclaire indirectement le travail des historiens d'aujourd'hui pour lesquels, plus que jamais, il n'est de science sans communication.

2 Pierre MONNET 